\title{
COVID-19 Vaccine Related Hyperosmolar Hyperglycemic State and Normalized Glycemia within 2 Months
}

\author{
Subhashini Yaturu*, Somayeh D. Azimi, Amy M. Allen, John Atkins \\ WJB Dorn VA Medical Center, University of South Carolina, Columbia, SC, USA \\ Email: *Subhashini.Yaturu@va.gov, *yaturu@yahoo.com
}

How to cite this paper: Yaturu, S., Azimi, S.D., Allen, A.M. and Atkins, J. (2022) COVID-19 Vaccine Related Hyperosmolar Hyperglycemic State and Normalized Glycemia within 2 Months. Journal of Diabetes Mellitus, 12, 12-17.

https://doi.org/10.4236/jdm.2022.121002

Received: October 13, 2021

Accepted: December 3, 2021

Published: December 6, 2021

Copyright $\odot 2022$ by author(s) and Scientific Research Publishing Inc. This work is licensed under the Creative Commons Attribution International License (CC BY 4.0).

http://creativecommons.org/licenses/by/4.0/ (c) (i) Open Access

\begin{abstract}
To protect from COVID-19 pandemic, several vaccines were developed infection with expected immunity against a SARS-CoV-2 infection. Short time side effects are reported. New onset diabetes was reported after SARS-CoV-2 infection. Here we report a case of new onset diabetes presenting with hyperosmolar hyperglycemic state, whose symptoms followed right after the second dose of Pfizer-BioNTech COVID-19 Vaccine. He is a 56-year old, obese Afro-American Veteran with no family history of diabetes and with $\mathrm{HbA1C}$ of 5.6 forty-five days prior to the hospitalization. He noted polyurea and excessive thirst following the second dose Pfizer-BioNTech COVID-19 vaccine. Hospitalized with hyperosmolar state and $\mathrm{HbA1C}$ of more than 14, he was treated initially with insulin drip and changed to basal, bolus regimen. In addition, he had new onset of oral thrush, requiring antifungal therapy. He needed higher doses of insulin during hospitalization and at discharge. He rapidly recovered and could be tapered off insulin in 4 months and recovered to normal glycemic state. We conclude that this is the second state to present with hyperosmolar state, and first case with rapid recovery of glycemic state.
\end{abstract}

\section{Keywords}

Diabetes, Pfizer-BioNTech COVID-19 Vaccine CAD, Hyperosmolar Hyperglycemic State, Anemia

\section{Introduction}

First descriptions of the hyperosmolar hyperglycemic state (HHS) was said to be in 1880s by von Frerichs and Dreschfeld. Current diagnostic criteria include a plasma glucose level of more than $600 \mathrm{mg} / \mathrm{dL}$ and increased effective plasma 
osmolality $>320 \mathrm{mOsm} / \mathrm{kg}$ in the absence of ketoacidosis. The incidence of HHS is estimated to be $<1 \%$ of hospital admissions of patients with diabetes. The reported mortality is between $10 \%$ and $20 \%$, which is about 10 times higher than the mortality rate in patients with diabetic ketoacidosis (DKA). To protect the public from COVID-19 pandemic several vaccines were developed and continue. These vaccines can protect those recipients from a SARS-CoV-2 infection with expected immunity against a SARS-CoV-2 infection. Short term side effects were reported but long side effects are not clear. Here we report a 56-year-old male with no family history of diabetes, with $\mathrm{HbA1C}$ of $5.6,45$ days prior to presentation with hyperosmolar state and $\mathrm{HbA1C}$ of more than 14 with symptoms of polyurea and nocturia following second dose of Pfizer-BioNTech COVID-19 vaccine.

\section{Case Report}

A 56-year-old obese Afro-American male with a past medical history of hypertension, primary hyperparathyroidism, goiter and primary hypothyroidism on levothyroxine, obesity and hyperlipidemia was hospitalized to medical intensive care unit with hyperosmolar hyperglycemic state with blood sugar more than 900 and acute renal insufficiency with creatinine of 2.7. His symptoms of polyurea and increased thirst following second dose of Pfizer-BioNTech COVID-19 vaccine. Thirst was so severe, drank three gallons of juice and water, couple of days prior to hospitalization. He felt confused and spilled gasoline on his clothes and became unsteady on the day of hospitalization. I addition, he had throat pain and mild cough, decreased visual acuity (blurring). Personal history significant for former smoker of 37 pack years. Quit smoking and alcohol use two years prior to hospitalization. Never heavy alcohol user. No family history of diabetes. His at home meds included antihypertensives, atorvastatin and levothyroxine $125 \mathrm{mcg}$ a day. Baseline labs and at discharge bmp are shown in Table 1. Physical exam revealed obese male with BMI of 33.5, cooperative and not in distress, appeared to be appropriate for stated age, well-built and nourished male. Had thyromegaly and oral thrush. No other abnormalities on physical exam.

He was hospitalized and appropriately treated in MICU with large doses of intravenous fluids, intra venous insulin drip of moderate doses and other supportive care. Later the insulin doses were transitioned to basal bolus insulins. Relevant diabetes related labs with changes over time are shown in Table 1. Blurring and visual acuity improved as sugars improved. Creatinine and eGFR normalized after IV fluids and treatment with insulin. Oral thrush was treated with oral nystatin suspension.

Follow up: Post discharge he received gradual tapering doses of insulin and later insulin was discontinued and recovered to normal glycemic state off anti diabetic meds. His HbA1C came down to 4.9 by 40 days after discharge. Rapid changes in blood counts at hospitalization also improved rapidly after discharge without any intervention as shown in Table 2. His glycemic state remains normal five months after discharge 
Table 1. With Basal metabolic parameters at admission and at follow up.

\begin{tabular}{ccccccccc}
\hline Date & $\mathrm{Na}$ & $\mathrm{K}$ & $\mathrm{Cl}$ & $\mathrm{CO}_{2}$ & $\mathrm{Glu}$ & $\mathrm{BUN}$ & $\mathrm{Cre}$ & eGFR \\
\hline $5 / 3 / 21$ & 118 & 6.1 & 82 & 13 & 997 & 38 & 2.7 & 30 \\
$5 / 4 / 21$ & 139 & 3.1 & 103 & 30 & 136 & 18 & 1.3 & $>60$ \\
$6 / 18 / 21$ & 139 & 4.4 & 109 & 19 & 158 & 19 & 1.1 & $>60$ \\
\hline
\end{tabular}

Na: Sodium; K: Potassium; Cl: Chloride; Glu: Glucose; BUN: Blood urea nitrogen; Cre: Creatinine; eGFR: estimated glomerular filtration rate.

Table 2. Change in blood counts over time.

\begin{tabular}{cccccc}
\hline Date & WBC & HGB & HCT & MCV & Platelets \\
\hline $5 / 3 / 21$ & 16.4 & 13.3 & 41.7 & 95.9 & 196 \\
$5 / 5 / 21$ & 11.7 & 9.9 & 30.6 & 92.3 & 141 \\
$5 / 14 / 21$ & 14.7 & 5.6 & 17.5 & 100.9 & 335 \\
$7 / 15 / 21$ & 11.7 & 12.5 & 337.4 & 92.4 & 243 \\
\hline
\end{tabular}

WBC: white cell count; HGB: Hemoglobin; HCT: Hematocrit; MCV: Mean Corpuscular Volume.

Interesting features:

1) Development of hyperosmolarity starting after the second dose of the vaccine in a patient with no family history of diabetes and $\mathrm{HbA1C}$ of 5.6, forty-five days prior to presentation with $\mathrm{HbA1C}$ of $>14$ and hyperosmolarity state.

2) Rapid rise and rapid recovery of glycemic state.

3) Rapid drop in blood counts and rapid recovery.

\section{Discussion}

Diabetes is high risk factor for severe complications including severe diabetic ketoacidosis, hyperosmolar state including high risk for death [1] [2] [3] [4] [5]. Severe metabolic complications of preexisting diabetes, including diabetic ketoacidosis and hyperosmolarity for which exceptionally high doses of insulin are warranted, have been observed in patients with COVID-19. There are several studies reporting new onset diabetes and COVID-19 [6]-[14]. Since angiotensin-converting enzyme 2 (ACE2) receptors are expressed (immunostaining) in several organs and but not in hepatocytes [15], it is considered possible that SARS-CoV-2 may lead to alterations in glucose metabolism and lead to complicating preexisting diabetes and or new onset diabetes [14]. In a study of SARS 1 pneumonia compared hyperglycemia (38.0\% vs. 9.8\%; $p=0.0001)$, suggesting that SARS caused lesions to that of non-SARS pneumonia, mortality was higher in patients within the pancreatic islets [16]. In pancreas, immunostaining for ACE2 protein was strong in the pancreatic islets but very weak in the exocrine tissues [16]. The above studies support the potential high risk in preexisting diabetes and new onset diabetes in COVID-19. Based on the immunostaining for ACE2 protein to be strong in the pancreatic islets but very weak in the exocrine 
tissues, Coate et al. postulated that the interaction of diabetes and SARS-CoV-2 is mediated by systemic inflammation and/or metabolic changes in other organs such as the liver, muscle, or adipose tissue [16]. Yang et al. reported that the localization of ACE2 expression in the endocrine part of the pancreas suggests that SARS coronavirus enters islets using ACE2 as its receptor and damages islets causing acute diabetes [17].

Serious Vaccine-related adverse events among BNT162b2 recipients from the trial include shoulder injury related to vaccine administration, right axillary lymphadenopathy, paroxysmal ventricular arrhythmia, and right leg paresthesia as reported from the safety and efficacy of the BNT162b2 mRNA COVID-19 vaccine study [18]. Hyperglycemia secondary to vaccine might have been relatively later and may explain the hyperosmolar state in our experience is a delayed side effect. We cannot explain the exact mechanism for severe and acute onset of diabetes leading to hyperosmolar state except that his c-peptide levels are low suggestive of pancreatic damage. There was one case report of hyperosmolar state [19], and one patient with pancreatitis after the vaccine [20].

In addition to glycemic changes, he had changes in hemoglobin and hematocrit, with recovery in 3 months. The possible explanation is the effect of vaccine on bone marrow with complete recovery.

\section{Conclusion}

Our patient presented with a hyperosmolar state and his symptoms started right after the second dose after receiving the BNT162b2 vaccine and had no other risk factors for the condition. Hence it is considered that the acute hyperglycemic state is the effect of the BNT162b2 vaccine. In addition, he recovered his pancreatic function to a prediabetic state within less than 2 months. This publication is for the clinicians to be aware of possible side effects of the vaccine as consideration and need for close follow-up care to avoid hypoglycemia as they recover. In addition to glycemic changes, he had changes in hemoglobin and hematocrit, with recovery in 3 months, probable effect on bone marrow.

\section{Acknowledgements}

All the authors received salary support from Veterans Health Administration

\section{Conflicts of Interest}

None of the authors have conflict of interest.

\section{References}

[1] Kempegowda, P., Melson, E., Johnson, A., Wallett, L., Thomas, L., Zhou, D., et al. (2021) Effect of COVID-19 on the Clinical Course of Diabetic Ketoacidosis (DKA) in People with Type 1 and Type 2 Diabetes. Endocrine Connections, 10, 371-377. https://doi.org/10.1530/EC-20-0567

[2] Reddy, P.K., Kuchay, M.S., Mehta, Y. and Mishra, S.K. (2020) Diabetic Ketoacidosis Precipitated by COVID-19: A Report of Two Cases and Review of Literature. Di- 
abetes \& Metabolic Syndrome, 14, 1459-1462.

https://doi.org/10.1016/j.dsx.2020.07.050

[3] Schmitt, J., Rahman, A.F. and Ashraf, A. (2020) Concurrent Diabetic Ketoacidosis with Hyperosmolality and/or Severe Hyperglycemia in Youth with Type 2 Diabetes. Endocrinology, Diabetes \& Metabolism, 3, Article ID: e00160.

https://doi.org/10.1002/edm2.160

[4] Chamorro-Pareja, N., Parthasarathy, S., Annam, J., Hoffman, J., Coyle, C. and Kishore, P. (2020) Letter to the Editor: Unexpected High Mortality in COVID-19 and Diabetic Ketoacidosis. Metabolism, 110, Article ID: 154301.

https://doi.org/10.1016/j.metabol.2020.154301

[5] Palermo, N.E., Sadhu, A.R. and McDonnell, M.E. (2020) Diabetic Ketoacidosis in COVID-19: Unique Concerns and Considerations. The Journal of Clinical Endocrinology \& Metabolism, 105, 2819-2829. https://doi.org/10.1210/clinem/dgaa360

[6] Mondal, S., DasGupta, R., Lodh, M., Gorai, R., Choudhury, B., Hazra, A.K., et al. (2021) Predictors of New-Onset Diabetic Ketoacidosis in Patients with Moderate to Severe COVID-19 Receiving Parenteral Glucocorticoids: A Prospective Single-Centre Study among Indian Type 2 Diabetes Patients. Diabetes \& Metabolic Syndrome, 15, 795-801. https://doi.org/10.1016/j.dsx.2021.03.022

[7] Aabdi, M., Aarab, A., Es-Saad, O., Malki, K., Bkiyar, H. and Housni, B. (2021) New-Onset Diabetes in Children during COVID-19: Clinical Case Report. Case Reports in Endocrinology, 2021, Article ID: 6654019. https://doi.org/10.1155/2021/6654019

[8] Sathish, T. and Cao, Y. (2021) Is Newly Diagnosed Diabetes as Frequent as Preexisting Diabetes in COVID-19 Patients? Diabetes \& Metabolic Syndrome, 15, 147-148. https://doi.org/10.1016/j.dsx.2020.12.024

[9] Naguib, M.N., Raymond, J.K. and Vidmar, A.P. (2021) New Onset Diabetes with Diabetic Ketoacidosis in a Child with Multisystem Inflammatory Syndrome Due to COVID-19. Journal of Pediatric Endocrinology and Metabolism, 34, 147-150. https://doi.org/10.1515/jpem-2020-0426

[10] Sathish, T., Tapp, R.J., Cooper, M.E. and Zimmet, P. (2021) Potential Metabolic and Inflammatory Pathways between COVID-19 and New-Onset Diabetes. Diabetes \& Metabolism, 47, Article ID: 101204. https://doi.org/10.1016/j.diabet.2020.10.002

[11] Singh, A.K. and Singh, R. (2020) Hyperglycemia without Diabetes and New-Onset Diabetes Are Both Associated with Poorer Outcomes in COVID-19. Diabetes Research and Clinical Practice, 167, Article ID: 108382.

https://doi.org/10.1016/j.diabres.2020.108382

[12] Gentile, S., Strollo, F., Mambro, A. and Ceriello, A. (2020) COVID-19, Ketoacidosis and New-Onset Diabetes: Are There Possible Cause and Effect Relationships among Them? Diabetes, Obesity and Metabolism, 22, 2507-2508. https://doi.org/10.1111/dom.14170

[13] Suwanwongse, K. and Shabarek, N. (2021) Newly Diagnosed Diabetes Mellitus, DKA, and COVID-19: Causality or Coincidence? A Report of THREE cases. Journal of Medical Virology, 93, 1150-1153. https://doi.org/10.1002/jmv.26339

[14] Rubino, F., Amiel, S.A., Zimmet, P., Alberti, G., Bornstein, S., Eckel, R.H., et al. (2020) New-Onset Diabetes in Covid-19. New England Journal of Medicine, 383, 789-790. https://doi.org/10.1056/NEJMc2018688

[15] Hamming, I., Timens, W., Bulthuis, M., Lely, A., Navis, G. and Van Goor, H. (2004) Tissue Distribution of ACE2 Protein, the Functional Receptor for SARS Coronavirus. A First Step in Understanding SARS Pathogenesis. Journal of Pathology, 203, 
631-637. https://doi.org/10.1002/path.1570

[16] Yang, J.K., Lin, S.S., Ji, X.J. and Guo, L.-M. (2010) Binding of SARS Coronavirus to Its Receptor Damages Islets and Causes Acute Diabetes. Acta Diabetologica, 47, 193-199. https://doi.org/10.1007/s00592-009-0109-4

[17] Coate, K.C., Cha, J., Shrestha, S., Wang, W., Gonçalves, L.M., Almaça, J., et al. (2020) SARS-CoV-2 Cell Entry Factors ACE2 and TMPRSS2 Are Expressed in the Microvasculature and Ducts of Human Pancreas but Are Not Enriched in $\beta$ Cells. Cell Metabolism, 32, 1028-1040 e4. https://doi.org/10.1016/j.cmet.2020.11.006

[18] Polack, F.P., Thomas, S.J., Kitchin, N., Absalon, J., Gurtman, A., Lockhart, S., et al. (2020) Safety and Efficacy of the BNT162b2 mRNA Covid-19 Vaccine. New England Journal of Medicine, 383, 2603-2615. https://doi.org/10.1056/NEJMoa2034577

[19] Abu-Rumaileh, M.A., Gharaibeh, A.M. and Gharaibeh, N.E. (2021) COVID-19 Vaccine and Hyperosmolar Hyperglycemic State. Cureus, 13, Article ID: e14125. https://doi.org/10.7759/cureus.14125

[20] Parkash, O., Sharko, A., Farooqi, A., Ying, G.W. and Sura, P. (2021) Acute Pancreatitis: A Possible Side Effect of COVID-19 Vaccine. Cureus, 13, Article ID: e14741. https://doi.org/10.7759/cureus.14741 